\title{
Research on risk based internal audit in Higher Vocational Colleges
}

\author{
Yan Qu \\ Qingdao Technical College, China. \\ quyan881@163.com
}

Keywords: Risk Based Internal Audit, Higher Vocational Colleges, Risk.

\begin{abstract}
Under the risk based internal audit model, the internal audit work of Higher Vocational Colleges starts from the first step to pay attention to all kinds of risks and runs through the identification and evaluation of risk in every link of the internal audit. Implementing risk based internal audit requires that internal audit institutions in higher vocational colleges must have some independence, and auditors should have stronger professional competency.
\end{abstract}

\section{Introduction}

The modern internal audit theory is gradually improved along with the development of Western capitalist economy, the evolution of management theory and the continuous change of entrusted economic responsibility. Risk based internal audit's theory was born in the latter of 1990s. It produces new requirements for management practice under the trend of information and globalization. It is based on management audit, taking account of financial audit and compliance audit, focusing on the strategic objectives of the organization and providing value-added services for the development of the organization. In contrast, the internal audit of China's higher vocational colleges still stays in the account audit stage. The purpose of the audit is to check the errors and prevent the fraud. The scope and extent of the internal audit is still limited. The new theory and new concept of risk based internal audit, the new technology and new means of risk based internal audit will improve the business level of internal audit in China's Higher Vocational Colleges and improve the internal audit service mode and quality of higher vocational college's internal management.

Every change of theory and practice of internal audit is closely related to the development and change of economic environment. Before the emergence of risk based internal audit, it has gone through a financial based internal audit focusing on reviewing account statements, aiming at correcting errors and correcting disadvantages. A business based internal audit focusing on analyzing and evaluating specific business activities and promoting business efficiency. In order to evaluate the effectiveness of the internal control system. System based internal audit is designed to help organization members to do their jobs effectively. In the early 1990s, as the global economic environment became more and more changeable and complex, risk management theory was widely applied, which brought pressure to internal audit. Internal audit began to turn to organizational risk and step into risk based internal audit stage. This was the last development stage of it. It requires internal auditors to focus on organizational risk and always focus on organizational risk in the process of audit. Taking the overall risk of organization as the focus of audit, it is intended to reveal organizational risk and put forward risk management recommendations through the evaluation of organization risk. So as to improve the operation of the organization and reflect the value-added function of the internal audit.

\section{The Implementation of Risk Based Internal Audit in Higher Vocational Colleges}

Risk based internal audit is a systematic and standardized way to evaluate the organization's risk management, control and supervision process. The audit plan should be worked out according to the risk level, and the key points of internal audit should be determined. Therefore, under the risk based internal audit model, the internal audit work of Higher Vocational Colleges starts from the first step to 
pay attention to all kinds of risks and runs through the identification and evaluation of risk in every link of the internal audit work.

\subsection{The Planning Stage of Internal Audit.}

The planning stage is the preparative stage for effective accomplishment of audit work. It includes making annual audit plan, confirming audit objects and determining audit plans for specific projects. Internal auditors in higher vocational colleges should take into consideration the internal and external environment of their units, considering their own characteristics and development tenet. Systematically identify, analyze and measure all kinds of risks faced by our school. A catalogue of risk factors suitable for the specific circumstances of our school is designed and worked out. Establishing a possible risk analysis model to quantify the risk elements. The order of audit items and audit priorities should be determined according to the risk level.

External factors and internal factors are the risk factors faced by higher vocational colleges. External risk factors include: national policy factors, regional economic development, geopolitical environment, population distribution and so on. The internal risk factors include: school development strategy, management risk, and financial risk and so on. It can be seen that the scope of risk based internal audit is far greater than that of traditional internal audit. Internal auditors pay close attention to risk factors from the perspective of the overall development of the organization, not just from the traditional financial and compliance perspective to identify and analyze risk factors.

When determining risk factors, internal auditors in higher vocational colleges should start from reality. We should focus on both the personality factors and the common factors. The risks faced by different vocational colleges have their own issues and different backgrounds. The risks faced by the same vocational college at different stages of development will not be exactly the same. We should change the past queuing rotation audit and the subjective judgment of auditors only. It focuses on risk assessment process, accumulates risk data, establishes risk models, and establishes audit plans based on quantitative risk indicators. At the same time, we should pay attention to the rational allocation of audit resources, concentrate the limited resources in high-risk areas, and make the efficiency of internal audit as high as possible.

\subsection{The Implementation Stage of Internal Audit.}

The risk based internal audit has changed the practice of the previous auditors simply taking the internal control system of the audited units as the audit object. Instead, it takes the purpose of internal control as the audit object and evaluates the control measures against the organizational goals. Attention should be paid to the relationship between control and risk. The work of review and evaluation should be carried out step by step, and the consistency between audit objectives and organizational goals should always be maintained. Risk based internal audit takes the route of goal, risk and control, and implements the audit procedure in three steps.

The first step is to identify the organizational goals. A comprehensive understanding of the functions and missions of the audited units. Determine its management level, refer to its department's development plan, determine its long-term goals and short-term goals, and distinguish the overall goals and level goals.

The second step is to analyze the risk factors that influence the organizational goals, determine the risk level, determine the audit priorities, and implement the audit process. Appropriate audit techniques and methods are applied for on-site investigation and evidence collection. Select appropriate risk factors and design risk models to quantify each risk factor.

In the internal audit practice of higher vocational colleges, we should focus on the compilation and reporting of budget of financial revenue and expenditure, examination and approval of important projects, the collection and payment of business fees, the management of extra budgetary funds, the procurement and management of equipment, and the implementation of infrastructure projects. Under necessary circumstances, we should review the formulation process of important decisions. At the same time, we should take account of the special risk factors such as audit severity and rectification. After the implementation of the necessary investigation and forensics and audit testing procedures, the risk factors are selected according to the actual situation of the audited units, and the risk identification, measurement and analysis models are established, and the risk factors are 
quantified. It objectively reflects the risk characteristics of the unit being tried. Then risk analysis and risk assessment are carried out to make in-depth and detailed analysis of the identified defects or problems. The reasons and consequences of audit findings are revealed, and audit conclusions and audit opinions are issued.

This process of risk assessment, investigation and evidence collection, analysis and summary is repeated throughout the whole audit process until all the audit points are fully revealed.

The third step is to put forward valuable risk management recommendations and improvement measures according to the actual situation of the units being audited.

\subsection{Reporting Phase of Internal Audit.}

After the end of the implementation stage of the audit, the internal auditors put forward the audit findings and audit recommendations on the basis of verified audit evidence and on the basis of risk assessment. The audit report should be issued to the relevant management, and the audited unit should be urged to correct problems and improve control in order to prevent the loss of potential risk.

For managers, the residual risk is acceptable for various reasons. Internal auditors should discuss with the management and integrate all factors. Ultimately determine acceptable levels of risk. In this way, compared with the traditional internal audit mode, the risk based internal audit plays a significant role in enhancing the advisory role and service function of the organization.

\subsection{The Follow-Up Audit Stage of Internal Audit.}

As a necessary procedure for internal audit, follow-up audit means tracking and reporting problems reflected in the report. It is not until the audited unit has taken corrective measures, achieved the expected effect, or the risk that the related management has undertaken the reported audit findings to not take corrective action.

Risk is the important factor that determines the scale and scope of follow-up audit in higher vocational colleges. The greater the risk, the deeper the follow-up audit will be, and the larger the scope will be. Therefore, the main contents of the follow-up audit in higher vocational colleges are the realization of the control goal and the reevaluation of the risk. The focus of the follow-up audit is the risk and influence caused by the failure of the control goal to be realized, but it should not only stay on how to implement the various audit proposals listed in the audit report.

Follow up audit is a key link of quality control, and it is also an important link to reflect the value of internal audit. In the previous internal audit of higher vocational colleges, the audit results and the rectification measures are generally paid more attention to, and the supervision and evaluation function of the follow-up audit is often ignored. Leading to rectification measures cannot be fully in place, part of the problems happens again. Higher vocational colleges should strictly perform follow-up audit procedures, ensure effective play of audit results and ensure effective play of value-added functions.

\section{The Implementation of Risk Based Internal Audit Requires Higher Vocational Colleges' Internal Audit Departments and Auditors.}

Compared with the traditional mode of internal audit, risk based internal audit pays more attention to the organization's strategy, goals and plans. We should pay attention to risk analysis from all aspects before, after and after the operation of the organization. It provides value-added services for managers at different levels and different functional departments. Therefore, internal audit institutions must have some independence. Auditors must have stronger professional competency.

\subsection{Enhance the Awareness of Risk and Improve the Skills of Risk Management.}

In recent years, the progress of science and technology and the development of economy have brought great benefits to the society, but at the same time, it has also brought risks that never occurred before. Risk management has become a management discipline which all over the world, especially in western developed countries, is widely regarded and promoted. Setting up risk awareness, implementing risk management concept and establishing risk management system have been widely applied in western countries. Internal audit also focuses on future risks related to organizational goals. Internal auditors in higher vocational colleges should set up risk awareness and constantly absorb and 
absorb advanced experience of risk management at home and abroad. We should enhance the skills of risk analysis and risk management, improve occupational sensitivity and improve the level of internal audit.

\subsection{Strengthening the Independence of Internal Audit.}

Most of the internal audit departments in Higher Vocational Colleges belong to the discipline inspection department, the financial department or the office. No matter in the form of organization or in essence, there is lack of necessary independence. There are few full-time auditors, unreasonable matching of knowledge structure, and uneven auditing staffs' professional level. To a large extent, it affects the independence and objectivity of internal audit.

In order to enhance the independence and objectivity of internal audit in higher vocational colleges, we must first ensure the independence of the internal audit department in the organization. Apart from the Department of finance, discipline inspection and supervision, we must equip the necessary personnel with regard to institutional setup. We must carry out the internal audit independently, and the internal audit institutions should directly belong to the leading leaders in higher vocational colleges. Report directly to the main leader. Secondly, internal auditors should enhance their learning and training and constantly improve their professionalism. Eliminate the interference from various factors of society and individuals, improve the ability to identify and manage all kinds of threat factors. Avoid subjective cognitive bias and ensure objectivity of audit results.

\subsection{Enhancing the Professional Competence of Internal Auditors.}

The International Association of internal auditors believes that under the risk based internal audit model, the internal auditors should have two qualities: knowledge skills and behavioral skills. Knowledge and skills include technology analysis, design and identification. Behavioral skills include personal skills, interpersonal skills and organizational skills. It can be seen that in addition to the requirements for knowledge and skills, risk based internal audit also emphasizes internal auditors' the characteristics of behavioral and psychological abilities.

Risk based internal audit puts forward higher requirements for professional competency of internal auditors in higher vocational colleges. From the past, we have only focused on the knowledge and skills of financial accounting and extended to the knowledge of management and other aspects of knowledge as well as the skills of communication, interpersonal relations, analysis and reasoning. Internal auditors can only adapt themselves to new professional requirements only by continuous learning and training.

\section{References}

[1]. Zing Shebang. Risk oriented internal audit research [D]. Master degree thesis of Jinan University, 2007, (14).

[2]. Yan Hue. Research on several issues of risk oriented internal audit [D]. Ph.D. Dissertation of Xiamen University, 2004, (60).

[3]. Internal Audit Association of China. Specific guidelines for internal auditing: No.1-- Audit plan. [EB/ OL]. Http: / / www. Cilia. Com. Can, 2008 - 06 - 01.

[4]. China Internal Audit Association. Internal audit practice standard [M]. Beijing: China Audit Press, 2003. 